\section{Microscopy}

\section{Coming Events}

2017

Novel Techniques in Microscopy

April 2-5, 2017

San Diego, CA

www.osa.org/en-us/meetings/global_calendar/events

novel_techniques_in_microscopy_\% $281 \% 29$

253rd ACS National Meeting \& Exposition April 2-6, 2017

San Francisco, CA

www.acs.org/content/acs/en/meetings/nationalmeetings/ meetings.html

\section{Focus on Microscopy 2017}

April 9-12, 2017

Bordeaux, France

www.focusonmicroscopy.org

\section{MRS Spring Meeting \& Exhibit}

April 17-21, 2017

Phoenix, AZ

www.mrs.org/spring2017

\section{Experimental Biology 2017}

April 22-26, 2017

Chicago, IL

http://experimentalbiology.org/2017/Home.aspx

\section{EMAS 2017 and IUMAS VII}

May 7-11, 2017

Konstanz, Germany

www.microbeamanalysis eu/events

Microscopy \& Microanalysis 2017

August 6-10, 2017

St. Louis, MO

www.microscopy.org

2018

Microscopy \& Microanalysis 2018

August 5-9, 2018

Baltimore, MD

www.microscopy.org

\section{9}

Microscopy \& Microanalysis 2019

August 4-8, 2019

Portland, OR

www.microscopy.org

\section{0}

Microscopy \& Microanalysis 2020

August 2-6, 2020

Milwaukee, WI

www.microscopy.org

\section{1}

Microscopy \& Microanalysis 2021

August 1-5, 2021

Pittsburgh, PA

www.microscopy.org

\section{2}

Microscopy \& Microanalysis 2022

July 31-August 4, 2022

Portland, OR

www.microscopy.org

More Meetings and Courses

Check the complete calendar near the back of this magazine.

\title{
A Microscopic Structure to Capture Dim Light
}

\author{
Stephen W. Carmichael \\ Mayo Clinic, Rochester, MN 55905 \\ carmichael.stephen@mayo.edu
}

Most plants are green because chlorophyll, the pigment commonly utilized for photosynthesis, absorbs blue (and some red) light for energy to drive photosynthesis, therefore reflecting green light. However, in extreme shade there is not enough energy available in the blue light so another mechanism is needed to provide energy for plants in this challenging environment. Recently Matthew Jacobs, Martin Lopez-Garcia, O.-Phart Phrathep, Tracy Lawson, Ruth Oulton, and Heather Whitney revealed microscopic organelles in leaves that may function as photonic crystals to enhance capturing energy from light [1]. Photonic crystals are periodic nanoscale structures that interact with light, resulting in a number of optical phenomena including lightharvesting. Photonic structures are widespread in nature where they are typically associated with structural color. A striking example of structural color is iridescent blue leaves as seen in a diverse range of tropical plants adapted to deep forest shade conditions. Jacobs et al. may be the first to present direct evidence of a function for this structural color in photosynthesis.

Blue iridescent leaves have been described in some species of the genus Begonia (see Figure 1). Unusual plastids containing highly ordered internal structures called iridoplasts have been observed in the surface tissue of leaves from these plants and could be the source of the blue coloration. However this has not been proven, and the biological significance has not been determined. To explore this, Jacobs et al. examined the micro- and nano-scopic morphology of the iridoplast in quantitative detail to
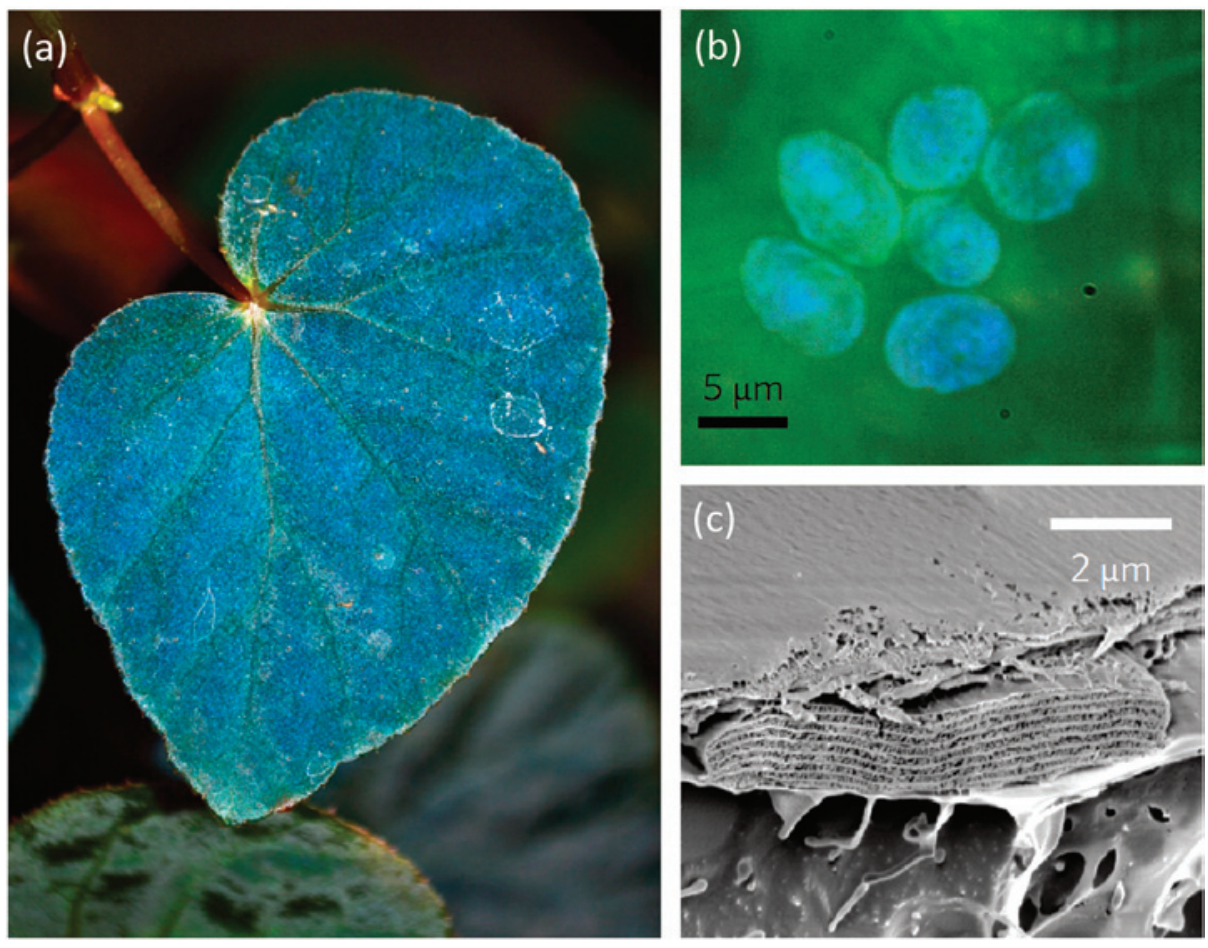

Figure 1: Blue leaf iridescence and iridoplasts in Begonia. (a) Photograph of a leaf of B. grandis $\times$ B. pavonina $(G \times P)$. (b) Microscopy image showing iridoplasts in an epidermal cell under brightfield epi-illumination. (c) Cryo-SEM image of a single iridoplast in Begoni GxP. Adapted by permission from Macmillan Publishers Ltd: Nature Plants 2 (11) Article number 16162 (2016). 
The C-flat ${ }^{\text {m }}$ Advantage

\section{C-flat ${ }^{\mathrm{TM}}$ leads to}

better data sets.

Made with patent pending technology, C-flat ${ }^{\mathrm{TM}}$

provides an ultra-flat surface that results in better

particle dispersion and more uniform ice thickness.

Patterning is done using deep-UV projection

lithography, ensuring the most accurate and

consistent hole shapes and sizes down to submicron

features. The precise methods by which $\mathrm{C}-$ flat $^{\mathrm{TM}}$ is

manufactured eliminate artifacts such as excess

carbon and edges around holes.

\section{C-flat ${ }^{\mathrm{TM}}$ is affordable}

$\mathrm{C}_{\text {-flat }}{ }^{\mathrm{TM}}$ is available in 25,50 , and 100 packs at a

per-grid price less than competing products.

\section{Applications}

C-flat holey carbon grids provide the ideal specimen support to achieve high resolution data in cryoTEM making C-flat the perfect choice for:

- Single particle analysis

- Cryo electron tomography

- Automated TEM analysis

\section{...EMS has itt}

CONTACT US FOR MORE INFORMATION...

\section{Electron}

Microscopy seiences

\author{
P.0. Box $550 \bullet 1560$ Industry Rd. \\ Hatfield, Pa 19440 \\ Tel: (215) 412-8400 • Fax: (215) 412-8450 \\ email: sgkcck@aol.com \\ or stacie@ems-secure.com
}

OUR MAIN INTERACTIVE WEBSITE:

\section{www.emsdiasum.com}

TO REQUEST A COPY

OF OUR CATALOG:

Www.emsdiasum.com/

requests/catalog

TO VIEW OUR

DIGITAL CATALOG:

catalog.emsdiasum.com

the premier holey carbon grid for

cryo-trañmission electron microscōoy

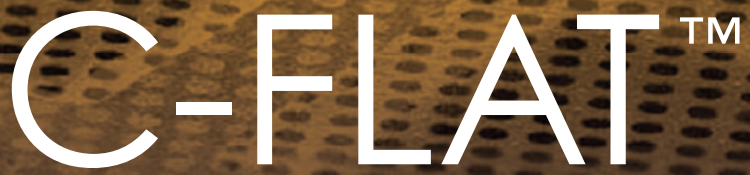

\section{Holey Carbon and Gold Grids for Gryo-TEM}

C-Flat ${ }^{\text {TM }}$ is a clean, ultra-flat holey carbon film TEM grid primarily used for Cryo TEM and Automated TEM. With a variety of available hole diameters, mesh size, film thicknesses, and mesh material, there is a C-Flat ${ }^{\text {Th }}$ product suitable for any application in the TEM.

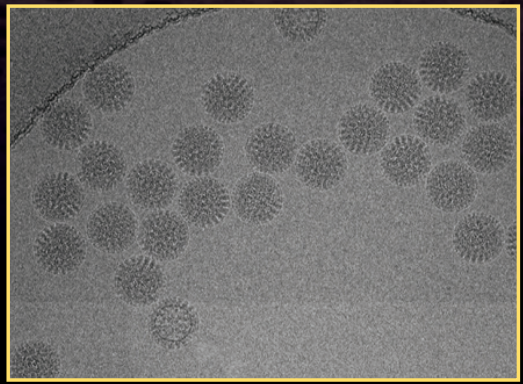

Frozen-hydrated Bacteriophage Capsid (data acquired on CF-1.2/1.4-4C).
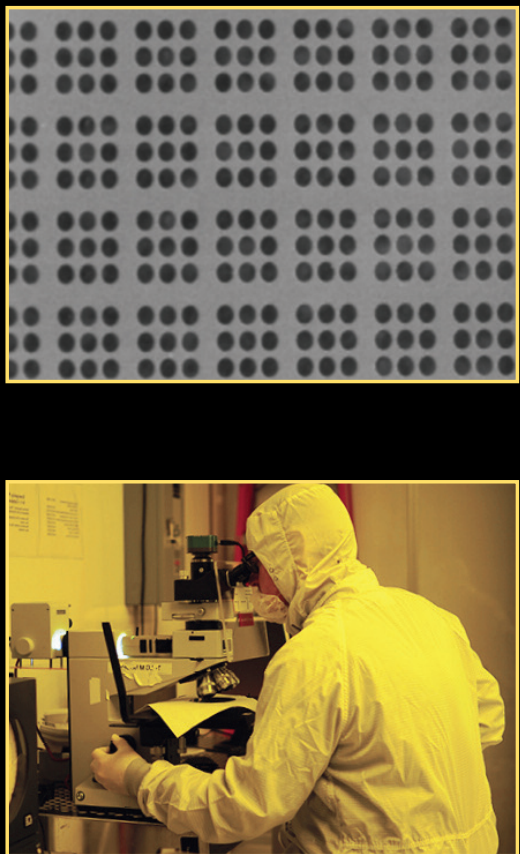

\section{Expanded Product Line}

The breadth of applications in cryoTEM necessitate a wide range of holey carbon film patterns. And now, with the recent expansion of the product line, a C-flat ${ }^{\text {TM }}$ holey carbon film is available for almost any application. Whether $600 \mathrm{~nm}$ holes are needed for very high magnifications with ultra-high resolution cameras or large open areas are needed for larger specimens, $\mathbf{C}-$ flat $^{\mathrm{TM}}$ is the perfect holey carbon grid.

\section{Consistent}

Researchers around the world have reported that the ultra-flat surface of $\mathrm{C}$-flat ${ }^{\text {TM }}$ leads to even ice thickness and uniform particle distribution, allowing for superior 3-D reconstructions. $2 \mu \mathrm{m}$ hole sizes are standard, but various hole sizes are available to accommodate different particle sizes and magnifications.

\section{Compatible}

C-flat $^{\text {TM }}$ provides a regular array of analysis sites compatible with automated data collection software such as Leginon. This compatibility, in combination with the more uniform ice thickness and particle distribution reported by numerous researchers, results in more high-quality target sites per grid.

\section{Clean}

C-Flat ${ }^{\text {TM }}$ uses no plastics or polymers in its production. This means C-Flat ${ }^{\mathrm{T} M}$ is shipped clean, so it's ready to use out of the box and requires no solvent washing steps prior to use, leading to less breakage of the holey carbon film. 
determine if it could be an optical model of the absorption and reflectance of the structure. Transmission electron microscopy (TEM) and scanning electron microscopy of frozen specimens (cryo-SEM) revealed a photonic crystal structure formed by a periodic arrangement of light-absorbing thylakoids. Thylakoids are membrane-bound compartments that are the site of the light-dependent reactions of photosynthesis. This structure enhances photosynthesis in two ways: by increasing light capture at the predominately green wavelengths available in shade conditions and also by absorbing the diminished light.

Iridoblasts therefore both reflect blue light and enhance green and red light absorption. This is vital to begonias that can be found in natural shade conditions where light can be attenuated more than a million-fold. Moreover, the spectral distribution of available light is shifted to the green wavelengths. Enhanced absorption of green light may therefore be a way to scavenge residual light. These and other factors suggest that iridoplasts are particularly adapted for low-light conditions where other plants would struggle to grow. Not only is this possibility significant for blue leaves that allow these plants to survive in shade, but it could also be applied to the design of synthetic structures to enhance light gathering in devices for solar energy production.

\section{Reference}

[1] M Jacobs et al., Nature Plants 2 (11) Article number 16162 (2016) doi: 10.1038/NPLANTS.2016.162.

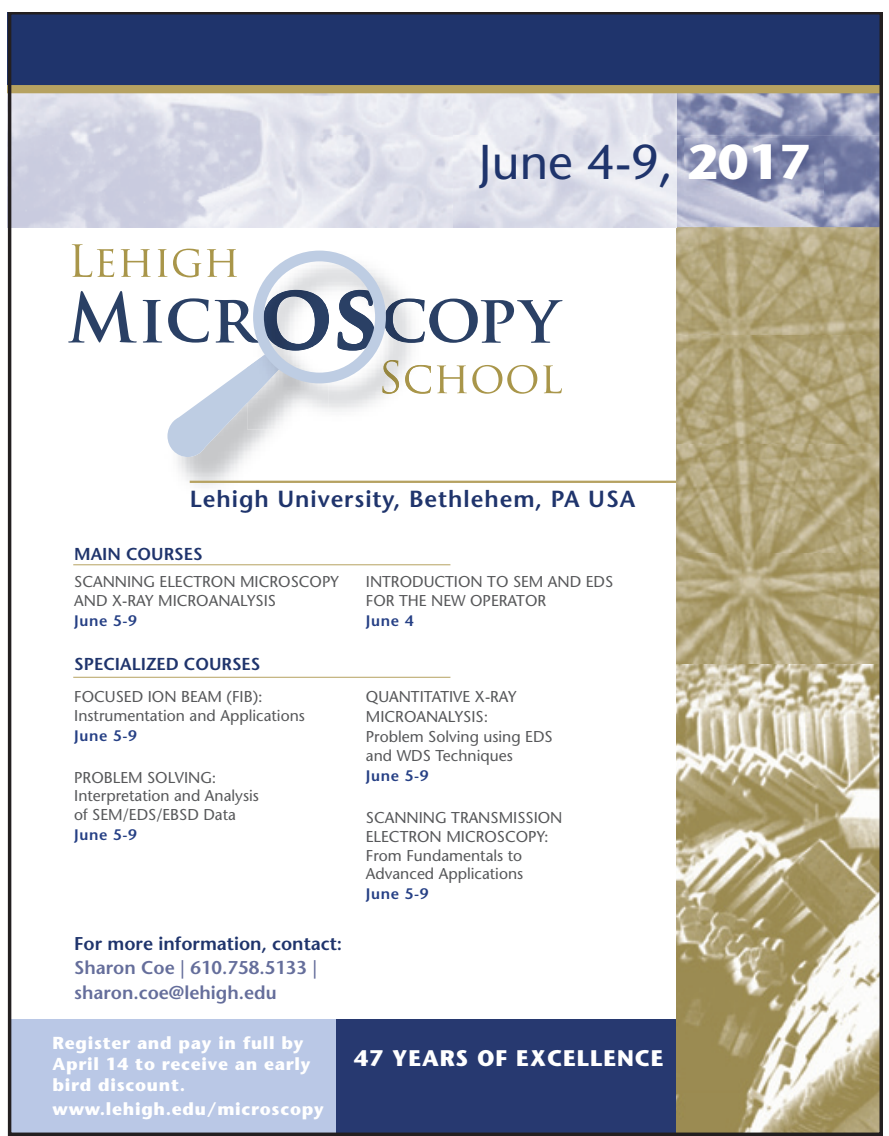

\section{(2) tousimis}
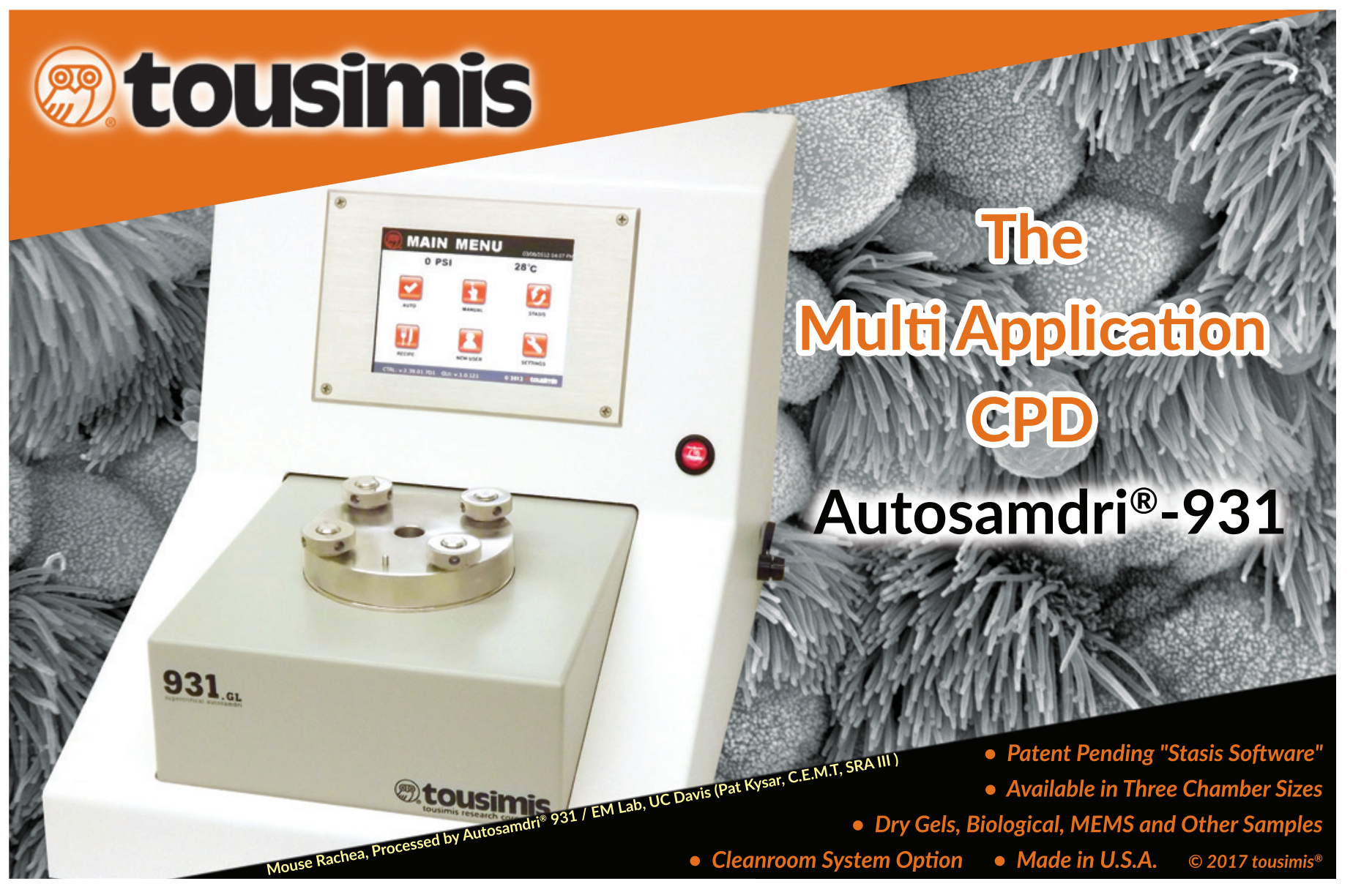


\section{Incomparable...}

...and still innovating

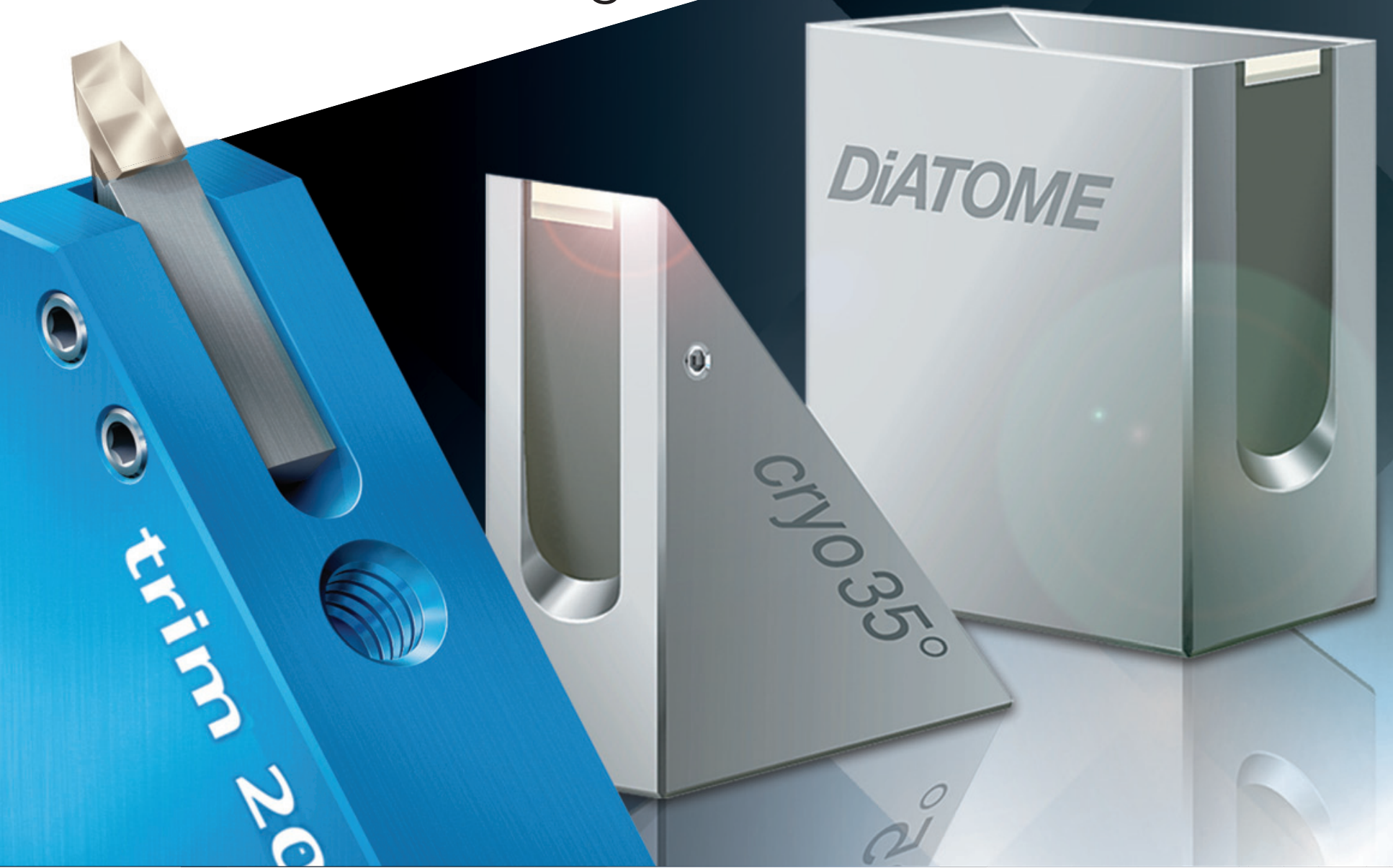

\section{DIATOME diamond knives}

ultra $45^{\circ}$ - cryo - histo ultra $35^{\circ}$ - histo jumbo cryo immuno • ultra sonic ultra AFM \& cryo AFM trimtool 20 - trimtool 45 trimtool 90

Over 40 years of development, manufacturing, and customer service

\section{DIATOME U.S.}

P.O. Box $550 \bullet 1560$ Industry Rd. • Hatfield, Pa 19440 Tel: (215) 412-8390 • Fax: (215) 412-8450

email: sgkcck@aol.com•www.emsdiasum.com

\section{Free customer service}

Sectioning tests with biological and material research specimens of all kinds. We send you the sections along with the surfaced sample, a report on the results obtained and a recommendation of a suitable knife. Complete discretion when working with proprietary samples.

Re-sharpening and reworking service

A re-sharpened Diatome diamond knife demonstrates the same high quality as a new knife. Even knives purchased in previous years can continue to be re-sharpened. The knives can be reworked into another type of knife for no extra charge, e.g. ultra to cryo or $45^{\circ}$ to $35^{\circ}$.

\section{Exchange service}

Whenever you exchange a knife we offer you a new DiATOME knife at an advantageous price. 